\title{
Immunization strategies to control a community-wide hepatitis A epidemic
}

\author{
K. M. THORBURN*, R. BOHORQUES, P. STEPAK, L. L. SMITH, \\ C. JOBB AND J. PALMER SMITH \\ Spokane Regional Health District, West 1101 College Avenue, Spokane, WA 99201, USA
}

(Accepted 3 April 2001)

\section{SUMMARY}

One fifth of 527 cases of hepatitis A occurred in self-identified injection drug users during a community-wide epidemic in Spokane County (Washington) in 1997-8. We hypothesized that an immunization campaign targeted at illicit drug users could control the epidemic. Starting in May 1998, hepatitis A vaccine was provided to individuals in jails and other sites frequented by illicit drug users. Volunteers at vaccination sites were surveyed about risk. Serial convenience samples of jail inmates who denied previous vaccination were anonymously tested for hepatitis A virus (HAV) immunoglobulin G (IgG). From May to December 1998, 2765 high-risk individuals were vaccinated against hepatitis A. The proportion of HAV IgG seropositive inmates increased from $30 \%$ to more than $50 \%$. Our findings suggest that vaccination along with naturally occurring infection increased the rate of hepatitis A immunity among illicit drug users during the final months of the epidemic. This supports the hypothesis that targeted immunization of high risk groups may shorten the natural history of a community-wide epidemic.

\section{INTRODUCTION}

Hepatitis A is second only to varicella as the most prevalent vaccine-preventable infection in the United States [1]. The annual incidence of hepatitis A is approximately 10/100000. Several western states, including Washington, have an annual incidence that is two or more times that national average. In these states, the virus is transmitted in cyclic, communitywide epidemics that tend to last from 1-3 years [2-5].

From 1989-91, Spokane County (Washington) had a community-wide epidemic of hepatitis A coincident with increased hepatitis A activity throughout the northwestern United States. Spokane County had 29 or fewer cases of hepatitis A per year, a rate lower than the Washington state average during 1992-6 (Spokane Regional Health District Epidemiology Unit, 1998). From September 1997 to 1998, Spokane County again experienced a community-wide epi-

* Author for correspondence. demic of hepatitis A. The annualized incidence was $97 \cdot 3 / 100000$, a total of 527 reported cases. The local health jurisdiction, Spokane Regional Health District, embarked on an aggressive campaign to control the spread of the virus, using the traditional approaches of community-wide and targeted education and postexposure immune globulin but also, actively promoting vaccination $[1,2,6-9]$. Targeted vaccination programmes were developed for illicit drug users and food workers.

This article describes the 1997-8 Spokane County hepatitis A epidemic and the Health District's vaccination efforts; in particular, the illicit drug user vaccination intervention.

\section{METHODS}

\section{Case data collection}

Hepatitis A cases are reported to local health jurisdictions in Washington. Most cases in the 
Spokane epidemic were reported by the local commercial laboratories when patients were seropositive for hepatitis A virus (HAV) immunoglobulin M (IgM). Spokane Regional Health District epidemiologists confirmed each case through interviews with the provider and infected individual. Cases that met the CDC/CSTE criteria (acute gastrointestinal illness, jaundice and/or abnormal liver function tests, HAV IgM seropositive) were entered into an ACCESS database developed at the Health District.

During the epidemic, cases were tracked temporally by the date that the Health District first received the report. Age, gender, geographic location and proportion using drugs by injection were regularly tabulated. Injection drug use was self-identified. Information about other illicit drug use was not uniformly collected. Annualized incidence was calculated with the 1998 Spokane County population reported from Targetpro by Mapinfo and Polk (406049).

\section{Food worker vaccination}

During the epidemic, public warnings and provision of immune globulin to restaurant patrons were necessary because of exposure to six infected food workers in four separate incidents occurring in November 1997, January, February and June 1998. The Health District, working with the restaurant industry, developed a voluntary at-cost vaccination programme for food workers in December 1997. Food worker vaccination increased markedly in February 1998 after a single restaurant with three infected workers was determined to have exposed thousands of patrons during the 1997 Christmas holiday season. The Health District provided certificates for public posting to establishments that vaccinated all of their food handlers. Food worker vaccination was intended to diminish the public risk of exposure but also of concern were the strain on public health resources, the immune globulin shortage and the impact on affected businesses after public announcements leading to large-scale administration of post-exposure prophylaxis.

\section{County-Wide activities}

In September 1997, the Health District began to mount an intensive campaign to control the trans- mission of hepatitis $\mathrm{A}$ in the community. Working with community partners, the campaign included educational outreach, through the media, pamphlets, training, and other promotional materials; postexposure prophylaxis and widespread vaccination. Hepatitis A vaccine was made widely available at cost and promoted by the Health District for all County residents starting in March 1998.

\section{Illicit drug user vaccination}

During the early months of the outbreak, it was noted that injection drug users (IDUS) and their household and other close contacts were a higher proportion of cases than among the sporadic cases during intraepidemic years. Information about injection drug use among cases was requested and regularly recorded by Health District epidemiologists. Information about cases among injection drug user contacts was anecdotal; epidemiologists heard of many such cases but did not record nor tabulate them. Illicit drug use has been reported as a risk association in other community-wide hepatitis A epidemics [10-14]. We postulated that illicit drug users were a reservoir for hepatitis A infection during the epidemic and that control of transmission in this group would terminate the epidemic.

In March 1998, the Washington state legislature appropriated $\$ 300000$ for a vaccination campaign in jurisdictions experiencing a hepatitis A epidemic. At the time, only Spokane County met the statutory criterion of an annualized case rate of greater than 100 per 100000 despite intensive use of traditional control efforts, including education and post-exposure prophylaxis. When the money became available to the Health District in May 1998, it was used to purchase vaccine to be provided at no charge to illicit drug users, to pay staff costs, and for project evaluation. Vaccines were provided through sites frequented by illicit drug users, including drug treatment facilities, homeless shelters, the Health District outreach and syringe exchange programme, the juvenile detention facility and most prominently, the County's jail and Geiger Correctional Centre. Participation in the vaccine programme was voluntary after informed consent. Individuals with a history of a jaundice illness during the previous year were dissuaded from having the vaccine but were not refused. Participants' names, social security number, birth date, and date and place of first dose were entered in a Health 


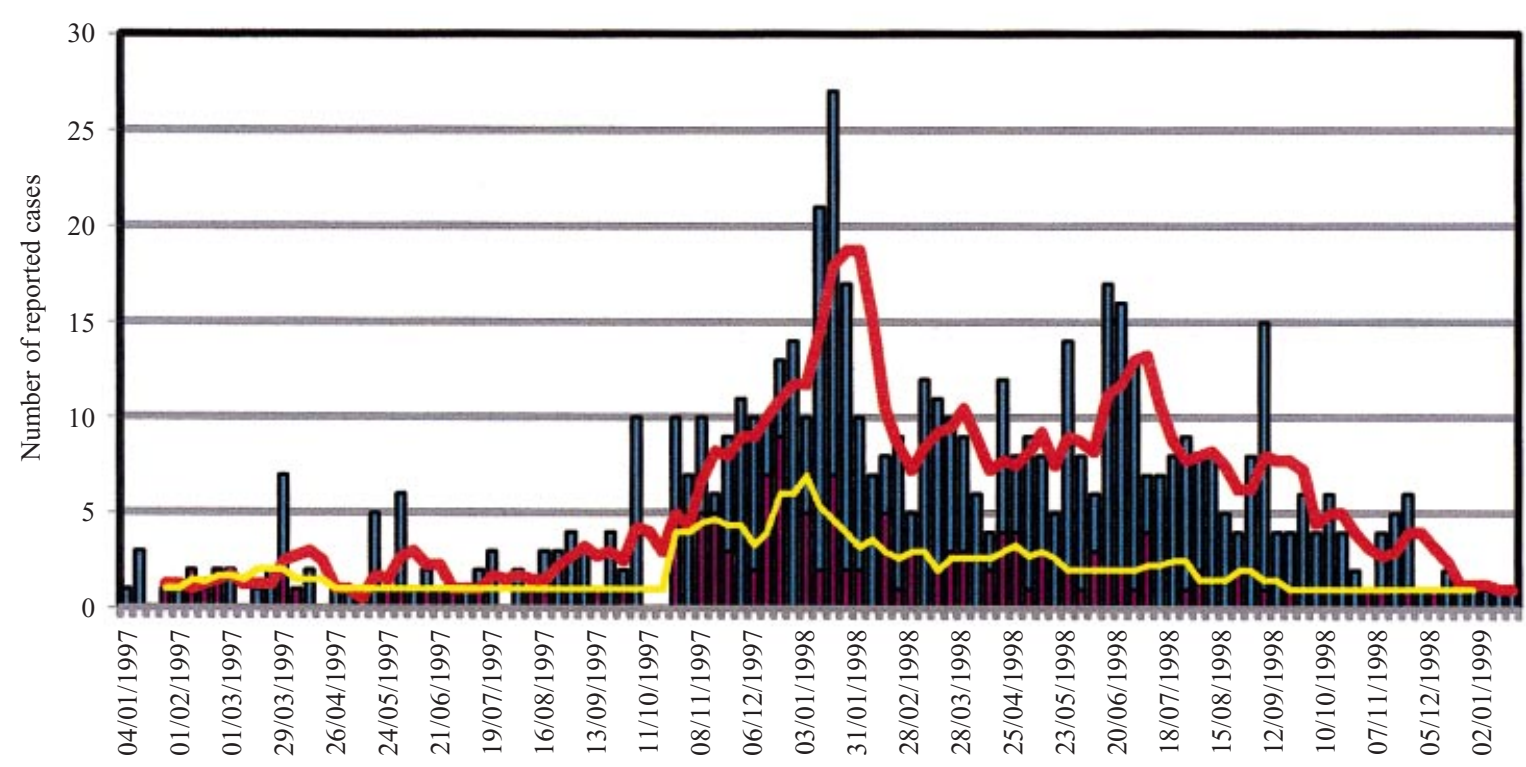

Week of the year and ending date of the week

\begin{tabular}{|ll|}
$\square$ & Count reported weekly \\
4 week period moving average & $\begin{array}{l}\text { IDU reported weekly } \\
\text { 4 week period moving average }\end{array}$ \\
\hline
\end{tabular}

Fig. 1. Hepatitis A cases and proportion of cases using drugs by injection reported by week to Spokane Regional Health District, 1997-8.

District registry and they were counselled to return for a second dose after 6 months.

\section{Project evaluation}

Two to 5 days before vaccine was offered at a facility, potential recipients were asked to voluntarily complete an anonymous survey to collect information about illicit drug use, Zip code of residence, number in household, monthly income and history of hepatitislike illness. Vaccination was later provided to those desiring it after written consent. The two were not linked in order to assure the anonymity of the survey whose purpose was to describe the risk characteristics of the population in the facility, particularly the proportion of illicit drug users. In June, September, and December 1998, incarcerated participants were asked to volunteer for blinded serum samples to test for HAV immunoglobulin $\mathrm{G}$ ( $\mathrm{IgG}$ ) in order to evaluate the susceptibility of the population being offered vaccine. The selection of prisoners was by convenience sampling, i.e. the first 50 willing prisoners who denied previous vaccination or serosampling. No rewards or incentives were offered for participation in the survey or serosampling. The project was approved by the Washington State Departments of Health/
Social and Health Services Institutional Review Board.

\section{RESULTS}

\section{Outbreak description}

In September 1997, Spokane Regional Health District began receiving a marked increase in confirmed hepatitis A case reports when compared to the previous 5 years. No point source was identified.

From 1 September 1997 to 31 December 1998, there were 527 cases of Hepatitis A in Spokane County, an annualized incidence of $97 \cdot 3$ cases/100000 (Fig. 1). January 1998 saw a peak of 75 cases, an annualized rate of $221 \cdot 6 / 100000$.

Typical of community-wide hepatitis A epidemics, young adult males predominated among the cases in Spokane County [1, 2, 11]. There were 318 males $(60 \cdot 3 \%)$. Three hundred and two $(57 \cdot 3 \%)$ of the cases were 19-39 years old (Fig. 2). The gender and age proportions remained relatively constant throughout the epidemic.

One hundred and seven cases $(20 \cdot 3 \%)$ reported injection drug use when questioned by the Health District interviewers. The proportion of IDUS among new cases decreased as the epidemic progressed, from 


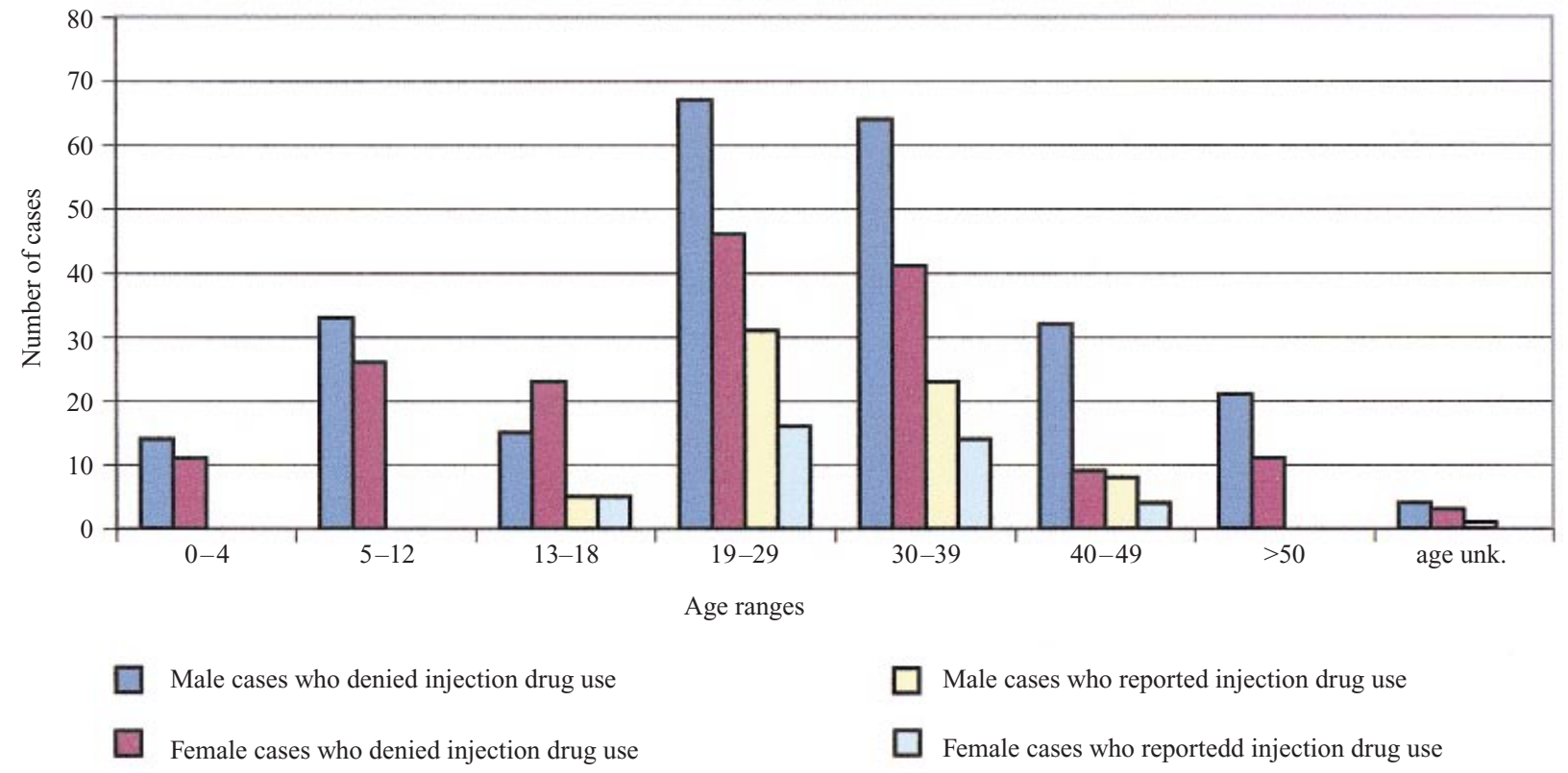

Fig. 2. Hepatitis A case characteristics in Spokane County from 1 September 1997 to 31 December 1998.

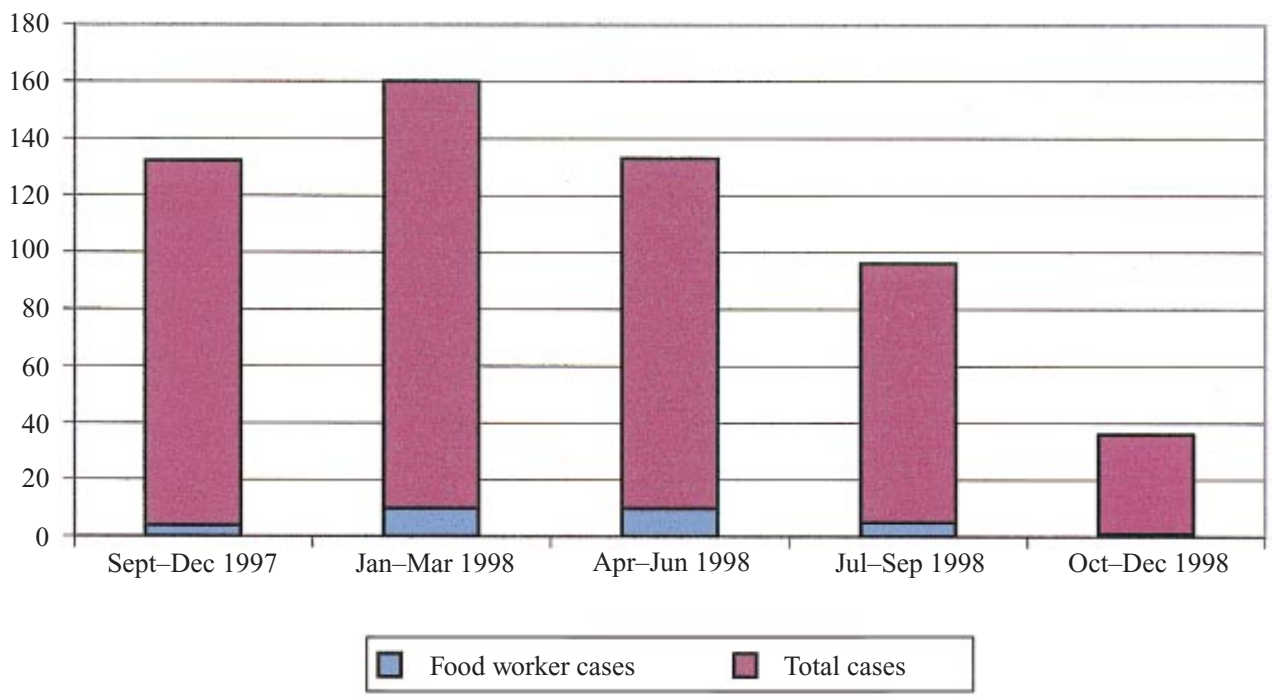

Fig. 3. Proportion of hepatitis A cases among food workers by quarter in Spokane County from 1 September 1997 to 31 December 1998.

$28.9 \%$ in the first 4 months (September-December 1997) to $14.3 \%$ in the last 3 months (OctoberDecember 1998).

By early 1999, the annualized rate of hepatitis A in Spokane County again decreased below the state average.

\section{Food worker vaccination}

There were 30 cases of hepatitis A among food workers, representing $5.8 \%$ of all cases, during the epidemic. The proportion of food worker cases peaked at $8.6 \%$ from April to June 1998 but was only $2.9 \%$ of cases during the last quarter of the epidemic (Fig. $3)$. There were no secondary cases traced to food worker exposure. A total of 9238 food workers were vaccinated between September 1997 and December 1998. Furthermore, the proportion of food worker cases prompting public warnings decreased as the epidemic progressed and there were none during the last 6 months of the epidemic. In most food worker cases after the first 4 months of the epidemic, Health 
Table 1. Characteristics of high-risk $H A V^{*}$ immunization outreach participants $(n=882)$

\begin{tabular}{llll}
\hline \hline & & $\begin{array}{l}\text { Correction } \\
\text { facilities } \dagger \\
(n=489)\end{array}$ & $\begin{array}{l}\text { Other } \\
\text { outreach } \\
\text { sites } \\
(n=393)\end{array}$ \\
\hline $\begin{array}{lllr}\text { Tllicit drug use } \\
\text { Injected drugs }\end{array}$ & $472(53 \cdot 5)$ & $300(61 \cdot 3)$ & $172(43 \cdot 7)$ \\
Drugs use & $227(25 \cdot 7)$ & $143(29 \cdot 2)$ & $84(21 \cdot 4)$ \\
$\quad \begin{array}{l}\text { Crack cocaine } \\
\text { Heroin }\end{array}$ & $313(35 \cdot 5)$ & $202(41 \cdot 3)$ & $111(28 \cdot 2)$ \\
$\quad \begin{array}{l}\text { Marijuana } \\
\text { Methamphet. }\end{array}$ & $465(52 \cdot 7)$ & $295(60 \cdot 3)$ & $170(43 \cdot 3)$ \\
\hline \hline
\end{tabular}

* Hepatitis A virus

$\dagger 117$ surveys missing one or more responses

$\$ 112$ surveys missing one or more responses

Table 2. $H A V^{*} I g G \dagger$ serologic testing of jail volunteers

\begin{tabular}{lll}
\hline $\begin{array}{l}\text { Month } \\
(1998)\end{array}$ & $\begin{array}{l}\text { Number } \\
\text { tested }\end{array}$ & $\begin{array}{l}\text { Number HAV IgG } \\
\text { seropositive }(\%)\end{array}$ \\
\hline Jun & 50 & $15(30 \cdot 0)$ \\
Sep & 42 & $24(57 \cdot 1)$ \\
Dec & 48 & $25(52 \cdot 1)$ \\
\hline \hline
\end{tabular}

*Hepatitis A virus

$\dagger$ Immunoglobulin G

District investigators found that the infected food worker posed minimal risk to the public due to adequate food handling and employee practices, particularly hand washing.

\section{Illicit drug user vaccination}

Early in the epidemic, vaccination charges were a barrier to immunizing illicit drug users, during outreach efforts both through the provider community and the Health District.

After receiving a state appropriation, from May through December 1998, 2765 immunizations were administered to high-risk individuals in sites frequented by illicit drug users. $81.1 \%$ were administered in the correctional and detention facilities. During this period, 882 individuals participated in anonymous surveys (Table 1). Four hundred and eighty-nine of the participants were correctional inmates and 393 were from the other outreach sites. $53.5 \%$ reported a history of illicit drug use. In addition, serum samples were collected for HAV IgG testing from 50, 42 and 48 volunteer previously unvaccinated prisoners respectively, in June, September and December 1998.

The results of the HAV IgG serosampling are shown in Table 2. Hepatitis A immunity, manifested by the proportion of volunteer prisoners with HAV IgG seropositivity, increased over time: $30 \%$ in June, $57 \cdot 1 \%$ in September and $52.1 \%$ in December. There were more refusals in December 1998 because many of the prisoners claimed to have already received one dose of the vaccine.

\section{DISCUSSION}

Community-wide hepatitis A epidemics are cyclic and naturally wane over time, probably due to subclinical or unrecognized infection with subsequent immunity in a large proportion of the affected population. These epidemics tend to be associated with a high proportion of infections among subpopulations (illicit drug users, homosexual men, children in day care) whose behaviours contribute to the transmission of the HAV during the epidemic. Targeting these involved subpopulations for hepatitis A immunization during a community-wide epidemic may control major pathways of transmission and shorten the natural history of the epidemic $[1,2,6,10]$.

From September 1997 through December 1998, Spokane County (Washington) had a communitywide epidemic of hepatitis A involving 527 cases for an annualized rate of 97.3/100000. The Spokane Regional Health District mounted an aggressive campaign, including education, post-exposure prophylaxis and immunizations, to control the epidemic.

Food workers were targeted for immunization because of their risk of amplifying transmission by exposing patrons $[2,6,15,16]$. Health District investigation of food worker cases determined significant exposure risks in four separate incidents and made public announcements urging patrons to receive post-exposure immune globulin. One such incident resulted in administration of more than 3000 doses of immune globulin in January 1998, during the height of an immune globulin shortage. The restaurant survived but suffered financially. The Health District began promoting vaccination of food workers at cost in December 1998 and provided a certificate for display to facilities that vaccinated all employees; restaurants markedly increased their participation in the programme after the January incident. 
A total of 9238 food workers received hepatitis A vaccine during the epidemic. The total number of food workers is unknown but during 1998 the Health District issued 12203 food cards to new food workers, which provides an estimate of the size of the work force in a high turnover industry. There were no secondary cases traced to food worker exposure even though they represented more than 1 in 20 cases during the epidemic. The food industry heightened its attention to food handling practices, particularly hand washing, as the epidemic progressed. In addition, food worker infection rates decreased in the last 6 months of the epidemic. Food industry cooperation during a community-wide hepatitis A epidemic is important and our data suggest that food worker vaccination may be a key strategy.

More than one fifth of the cases reported injection drug use to Health District interviewers. Illicit drug users were targeted for vaccination because they were assumed to be a reservoir of cases related to much of the disease transmission during the epidemic. Poor hygiene during drug-use rituals and related behaviours has previously been postulated to be a contributor to HAV transmission in community-wide epidemics [11-14].

Due to the barrier of cost, the Health District was unable to initiate an intensive hepatitis A immunization campaign of illicit drug users until it amassed sufficient resources to provide free vaccine 8 months into the epidemic. 2765 immunizations were administered from May to December 1998 in drug treatment facilities, homeless shelters, the Health District's outreach and syringe exchange programme, and Spokane County correctional facilities, including juvenile detention. This represents nearly one quarter of the estimated 11150 low-income illicit drug users in Spokane County in 1998 (Washington State Department of Social and Health Services, Division of Alcohol and Substance Abuse, 2000).

Another challenge for public health interventions directed to illicit drug users is difficulty reaching them because of societal marginalization. While there are some logistic difficulties because of security needs, correctional facilities afford an opportunity to reach large numbers of illicit drug users with mass public health interventions. For the Spokane intervention, correctional facilities were selected as the principal sites for immunization outreach clinics to access illicit drug users because of the high proportion of prisoners who use such drugs. Anonymous surveys confirmed that $61.3 \%$ of the prisoners participating in the programme reported a history of illicit drug use. Although the surveys were anonymous, only a fraction of residents at the various facilities completed them and many had missing responses. The selfreporting may have contributed to misclassification bias but other data, including jail population reports, suggest that our proportion is low.

Serosampling was performed to determine the disease susceptibility of the incarcerated population. Each batch of serosamples was collected from the first willing prisoners as they were individually approached by Health District Staff being escorted through the jail i.e. convenience sampling. This sampling technique creates possible selection bias. Hepatitis A was prominently featured in the media during the epidemic. Prisoners with greater awareness because of direct involvement as a case and association with the media coverage may have been more likely to come forward as volunteers. It is also notable that a larger proportion of prisoners refused testing in December than in the earlier two sessions because they claimed that they had already received the vaccine.

Illicit drug users were assumed to be an important source of transmission of HAV during the epidemic. Evidence of increasing immunity within a previously unvaccinated sample of this subpopulation and vaccination of a large number of illicit drug users correlated with waning and eventual termination of the epidemic. The temporal association of increasing immunity, both naturally and vaccination acquired, with the decline of the epidemic suggests that targeted vaccination to increase the level of immunity in a subpopulation with high rates of HAV transmission might be successful in aborting a community-wide epidemic. The challenge is amassing the resources early enough in the epidemic to impact the natural cyclic course.

\section{ACKNOWLEDGEMENTS}

SmithKline Beecham provided some funding of staff costs for administering vaccine. Dr Thorburn received a speaker's honorarium from Merck and Company.

\section{REFERENCES}

1. Bell BP, Shapiro CN, Alter MJ, et al. The diverse patterns of hepatitis A epidemiology in the United States-implications for vaccination strategies. J Infect Dis 1998 ; 178: 1579-84.

2. Centres for Disease Control and Prevention. Prevention of hepatitis A through active or passive immunization: 
recommendations of the Advisory Committee on Immunization Practices (ACIP). MMWR 1999; 48 (RR-12): 1-38.

3. Levinthal G, Ray M. Hepatitis A: From epidemic jaundice to vaccine-preventable disease. Gastroenterol 1996; 4: 107-17.

4. Lemon SM. Type A hepatitis: epidemiology, diagnosis, and prevention. Clin Chem 1997; 43: 1494-9.

5. American Academy of Paediatrics. Prevention of hepatitis A infections: guidelines for use of hepatitis A vaccine and immune globulin. Pediatrics 1996; 98: 1207-15.

6. Centres for Disease Control and Prevention. Prevention of hepatitis A through active or passive immunization: recommendations of the Advisory Committee on Immunization Practices (ACIP). MMWR 1996; 45 (RR-15): 1-30.

7. Craig AS, Sockwell DC, Schaffner W, et al. Use of hepatitis A vaccine in a community-wide outbreak of hepatitis A. Clin Infect Dis 1998; 27 : 531-5.

8. McMahon B J, Beller M, Williams J, et al. A program to control an outbreak of hepatitis A in Alaska by using an inactivated hepatitis A vaccine. Arch Pediatr Adolesc Med 1996; 150: 733-9.

9. Levy MJ, Herrera JL, Dipalma JA. Immune globulin and vaccine therapy to prevent hepatitis A infection. Am J Med 1998; 105: 416-23.
10. Hutin YJF, Bell BP, Marshall KLE, et al. Identifying target groups for a potential vaccination program during a hepatitis A community-wide outbreak. Am J Publ Hlth 1999; 89: 918-21.

11. Grinde B, Stene-Johansen K, Sharma B, et al. Characterization of an epidemic of hepatitis A virus involving intravenous drug abusers-infection by needle sharing? J Med Virol 1997; 53: 69-75.

12. Ferson MJ, Young LC, Stokes ML. Changing epidemiology of hepatitis A in the 1990s in Sydney, Australia. Epidemiol Infect 1998; 121: 631-6.

13. Collins J. Fecal percutaneous transmission of hepatitis A involving methamphetamine users in Iowa. An interview with Patricia Quinlisk, MD, MPH, State Epidemiologist/Medical Director, Iowa Department of Health, and Yvan Hutin, MD, Epidemic Intelligence Service officer, Centres for Disease Control and Prevention. Environ Health 1998; June: 26-29.

14. Hutin YF, Sabin KM, Hutwagner LC, et al. Multiple modes of hepatitis A virus transmission among methamphetamine users. Am J Epidemiol 2000; 152: 186-92.

15. Bader TF. Hepatitis A vaccine. Am J Gastroenterol 1996; 91 : 217-22.

16. Hepatitis A vaccine for food handlers (clinical briefs). Am Fam Physician 1998; 57: 878. 